Jurnal Spektrum Komunikasi Vol 6 No. 2 Desember, 2018

\title{
STRATEGI PUBLISITAS DALAM MENINGKATKAN BRAND AWARENESS RS HUSADA UTAMA SURABAYA
}

\section{PUBLICITY STRATEGY TO INCREASING RS HUSADA UTAMA SURABAYA BRAND AWARENESS}

\author{
Dhindya Puspa Hidayat \\ Busana Rumah Modern, Surabaya \\ Email : dhindyapuspa@yahoo.co.id
}

\begin{abstract}
Husada Utama Hospital is one of hospital which has established for 11 years. It's inaugurated in 2006, it's located on Jl.Prof. Dr. Mustopo 31 - 35 Surabaya. It's got recommended from East Java Province Health Office, as public hospital B level. With the code of ethics promotions at the hospital and Husada Utama Hospital is a hospital that's still just standing, making researchers interested to know how the Husada Utama Hospital introduces and inform health services owned by The Husada Utama Hospital to public. The research aims to know the publicity strategy implemented by Husada Utama Hospital in improving brand awareness. The research method use in this research is qualitative descriptive by conducting in depth interview. The brand awareness strategy established by Husada Utama Hospital is utilizing the high and magnificent hospital building form, then the comfortable and complete facilities, and the last some program which are not have by the other hospital. So, it made hospital is easy to be remembered by the society. In this research, it's seen that the brand awareness of Husada Utama Hospital in improving publicity is by giving health education to the society through mass media, seminar, and various activities. The brand awareness strategy created by Husada Utama Hospital includes 4 indicators namely recall, recognition, purchase, and consumptions.
\end{abstract}

Keywords: brand awareness, publicity, RS Husada Utama

\begin{abstract}
ABSTRAK
RS Husada Utama adalah salah satu Rumah Sakit yang baru 11 tahun berdiri. Diresmikan pada tahun 2006, Rumah sakit yang berlokasi di Jl. Prof. Dr. Mustopo 31 - 35 Surabaya ini mendapat rekomendasi dari Dinas Kesehatan Propinsi Jawa Timur sebagai rumah sakit umum kelas B. Dengan adanya kode etik promosi pada rumah sakit dan RS Husada Utama adalah rumah sakit yang masih baru saja berdiri, membuat peneliti tertarik untuk mengetahui bagaimana cara RS Husada Utama memperkenalkan dan menginformasikan layanan kesehatan yang dimiliki oleh RS Husada Utama kepada masyarakat. Penelitian ini bertujuan untuk mengetahui strategi publisitas yang diterapkan oleh RS Husada Utama dalam meningkatkan brand awareness. Metode penelitian yang digunakan dalam penelitian ini adalah kualitatif deskriptif dengan melakukan wawancara mendalam (indepth interview). Strategi brand awareness yang dibentuk RS Husada Utama adalah memanfaatkan bentuk bangunan Rumah Sakit yang tinggi dan megah, kemudian fasilitas yang nyaman dan lengkap, serta beberapa program yang tidak banyak dimiliki RS lain.
\end{abstract}

ISSN 2338 - 0861 (cetak); e-ISSN 2621 - 8712 (online)

website : http://spektrum.stikosa-aws.ac.id 
Hal tersebut membuat RS HU mudah diingat oleh masyarakat. Dalam penelitian ini terlihat bahwa publisitas RS Husada Utama dalam meningkatkan brand awareness adalah dengan memberikan edukasi kesehatan kepada masyarakat melalui media massa, seminar, dan berbagai kegiatan. Strategi brand awareness yang diciptakan oleh RS Husada Utama meliputi 4 indikator yaitu recall, recognition, purchase, and consumptions.

Kata-kata Kunci: brand awareness, publisitas, RS Husada Utama

\section{PENDAHULUAN}

Rumah Sakit Husada Utama Surabaya merupakan salah satu rumah sakit yang menarik untuk dikaji lebih dalam. Hal tersebut dikarenakan peneliti tertarik dengan berbagai cara yang dilakukan RS Husada Utama untuk memberikan informasi, mengingatkan tentang brand Rumah Sakit Husada Utama kepada pasien ataupun calon pasien.

Dengan keberadaan RS

Husada Utama di lingkup Rumah Sakit tersebut, persaingan untuk menggaet pelanggan akan semakin terasa. Hal ini tentunya membuat suatu tantangan sendiri bagi RS Husada Utama untuk mengenalkan kepada calon pasien dan mengingatkan pada pelanggan tentang brand RS Husada Utama. Sebelumnya, peneliti mengetahui salah satu cara yang dilakukan RS. Husada Utama untuk mengenalkan diri kepada konsumen dengan melakukan talkshow di beberapa radio. Talkshow yang narasumbernya adalah dokter Rumah Sakit Husada Utama. Para dokter memberikan informasi mengenai kesahatan bagi para pendengar radio. Salah satu radio yang digunakan RS Husada Utama ialah radio Suara Akbar Surabaya (SAS). Pendengar diajak untuk memahami edukasi kesehatan yang dapat diterapkan pada dirinya dan keluarga. Tips dan trik dapat diserap melalui pembahasan materi dokter secara jelas.
Beberapa radio yang pernah didengar peneliti mengadakan talkshow dengan menghadirkan dokter dari Husada Utama adalah Radio SAS, Radio Global Female, dan Radio Sindo, dan mungkin saja bisa lebih dari 3 radio tersebut Husada Utama mengadakan talkshow. Kegiatan Husada Utama saat menjadi narasumber di beberapa talkshow dapat dilihat pada akun instagram Husada Utama yaitu @rs.husadautama.

Menurut peneliti, hal diatas adalah salah satu strategi pemasaran yang dilakukan RS. Husada Utama untuk menarik konsumen menggunakan jasa RS. Husada Utama. Peneliti juga pernah melihat banner tentang kompetisi Fashion Hijab yang diadakan oleh RS Husada Utama, banner tersebut dipasang di depan Rumah Sakit yang bertempat di Jl. Prof. Dr. Mustopo ini. Pemberitaan tentang kegiatan RS HU gelar fashion show busana muslim, peneliti menemukan pada salah satu situs berita yaitu www.bicarasurabaya.com. Menurut peneliti, hal tersebut mungkin adalah salah satu strategi yang digunakan oleh humas dan marketing RS Husada Utama, untuk dapat mengenalkan Rumah Sakit kepada calon konsumen. Letak geografis dari RS. Husada Utama berada di Jl. Prof. Dr. Mustopo no $\quad 31 \quad-35$ Surabaya. Lokasi ini berdekatan dengan beberapa Rumah Sakit besar dan ternama. Rumah Sakit

ISSN 2338 - 0861 (cetak); e-ISSN 2621 - 8712 (online)

website : http://spektrum.stikosa-aws.ac.id 
ini berdiri diantara RSUD Dr. Soetomo, RS. Graha Amerta. Salah satu kompetitor yang berdiri di wilayah sekitar RS Husada Utama Surabaya adalah RSUD Dr.Soetomo. Pada tahun 1938, peletakan batu pertama RS Central Buggerlijk Ziekenhuis (CBZ) oleh Pemerintah Belanda di Desa Karangmenjangan, lalu mulai diresmikan menjadi RSUD Dr, Soetomo pada tahun 1964. RSUD Dr. Soetomo merupakan rumah sakit tipe A, yang didukung dengan SDM yang berjumlah kisaran 4900. Dr. Soetomo juga memiliki fasilitas utama yaitu :Pusat Diagnostik Terpadu, Instalasi Rawat Inap, Instalasi Rawat Jalan, dan Instalasi Rawat Darurat.

Menurut Surat Keputusan

Menteri Kesehatan Republik Indonesia No.HK.03.05/I/2330/11 tentang Penetapan Kelas Rumah Sakit Umum Husada Utama Surabaya, Provinsi Jawa Timur sebagai Rumah Saakit Umum Kelas B. Dimana peneliti mendapatkan informasi dari Humas RS HU bahwa Rumah Sakit lain di Surabaya yang merupakan tipe B salah satunya adalah RS Siloam.

Tipe rumah sakit berdasarkan Permenkes RI nomor 986/Menkes/Per/1 1/1992 meliputi pelayanan rumah sakit umum pemerintah department kesehatan dan pemerintah daerah yang diklasifikasikan menjadi kelas/ tipe A,B,C,D, dan E, perbedaanya sebagai berikut. Rumah Sakit tipe Aadalah rumah sakit yang mampu memberikan pelayanan kedokteran spesialis dan subspesialis luas oleh pemerintah, rumah sakit ini telah ditetapkan sebagai tempat pelayanan rujukan tertinggi atau sering disebut rumah sakit pusat.

Selanjutnya, rumah sakit tipe B adalah rumah sakit yang mampu memberikan pelayanan kedokteran medik spesialis luas dan subspesialis terbatas. Kemudian, rumah sakit tipe $\mathrm{C}$ adalah rumah sakit yang mampu memberikan pelayanan kedokteran subspesialis terbatas. Lalu ada rumah sakit tipe D adalah rumah sakit yang memberikan pelayanan kedokteran umum dan kedokteran gigi, dan yang terakhir rumah sakit tipe E merupakan rumah sakit khusus. Pada saat ini banyak tipe $\mathrm{E}$ yang didirikan oleh pemerintah, seperti rumah sakit jiwa, rumah sakit jantung.

Dari sekilas perihal yang diketahui peneliti tersebut, peneliti makin tertarik untuk mengkajinya lebih dalam tentang strategi komunikasi pemasaran dari RS Husada Utama. Berbicara tentang strategi komunikasi pemasaran, dikenal dengan adanya sarana bauran pemasaran promosi yang meliputi periklanan, penjualan personal, hubungan masyarakat, pemasaran langsung, dan promosi penjualan.

Promosi Rumah Sakit adalah salah satu bentuk dari pemasaran Rumah Sakit (Hospital Marketing), hal tersebut dengan cara penyebarluasan informasi tentang jasa pelayanan rumah sakit serta kondisi rumah sakit itu sendiri secara jujur, mendidik, informatif dan dapat membuat seseorang memahami tentang pelayanan kesehatan yang akan didapatkannya.

Perluasan peran komunikasi pemasaran bertanggung jawab untuk menghasilkan suatu ekuitas merek. Ekuitas merek berdasarkan perspektif konsumen, adalah salah satu hal yang penting untuk dapat mempertahankan konsumen menggunakan jasa sebuah Rumah Sakit tersebut. Sebuah merek memiliki ekuitas sampai pada tingkat bahwa orang familiar dengan merek tersebut mempunyai ingatan asosiasi merek yang baik (favorable), kuat, dan unik. 
Mengenai ekuitas merek, ada 2 bentuk pengetahuan terkait tentang merek yaitu kesadaran merek (brand awareness) dan citra merek (brand image). Salah satu hal yang dapat menjadikan konsumen tetap sadar dan ingat tentang merek RS. Husada Utama adalah dengan membentuk suatu brand awareness.

Dengan strategi komunikasi pemasaran yang terencana dengan baik akan membawa dampak yang baik pada peningkatan brand awareness sebuah perusahaan. Brand Awareness adalah kemampuan dari seorang calon konsumen untuk mengenali (recognize) atau mengingat (recall) suatu merek yang merupakan bagian dari suatu kategori produk. Brand Awareness mencakup asset asset terpenting bisnis, yang terdiri dari asset tak berwujud (intangible asset) - nama (citra) perusahaan, merek, simbol, slogan dan asosiasinya, persepsi kualitas, kepedulian merek, basis pelanggan, serta sumber daya seperti hak paten, trademark, dan hubungan dengan dealer semuanya merupakan sumber utama keunggulan bersaing dan pendapatan di masa depan.

"Setia melayani dengan kasih sayang", merupakan motto RS Husada Utama yang dicantumkan dalam web resminya. Motto tersebut juga salah satu cara untuk dapat mengenalkan pada calon konsumen tentang RS Husada Utama Surabaya. Oleh karena itu peneliti juga ingin mengetahui berbagai strategi lain yang digunakan untuk menciptakan brand awareness RS Husada Utama.

Hubungan media dan pers merupakan sebagai alat pendukung untuk kepentingan proses publikasi dan publisitas program kerja atau kelancaran aktivitas komunikasi humas dengan pihak publik. Strategi brand awareness yang sudah dibuat, tentunya membutuhkan publikasi untuk meningkatkan publisitas.

Dari permasalahan diatas, oleh karena itu peneliti ingin mengkaji tentang strategi publisitas dalam meningkatkan brand awareness RS Husada Utama. Peneliti mengkaji penelitian ini dengan menggunakan teknik wawancara mendalam pada pihak yang terkait dengan komunikasi pemasaran seperti humas dan marketing RS Husada Utama Surabaya.

\section{METODOLOGI}

Metode kualitatif digunakan dalam penelitian ini, karena kajian dalam penelitian bersifat dinamis dan penuh makna sehingga tidak mungkin data pada situasi sosial tersebut dijaring dengan metode penlitian kuantitatif dengan intrumen seperti tes dan kusioner. Selain itu peneliti bermaksud memahami situasi sosial secara mendalam, menemukan pola, hipotesis, dan simpulan.

Penelitian deksriptif yaitu mengumpulkan data berdasarkan faktor-faktor yang menjadi pendukung terhadap objek penelitian, kemudian menganalisa faktor-faktor tersebut untuk dicari peranannya. Sehingga penelitian deksriptif kualitatif merupakan jenis penelitian yang menghasilkan penemuan penemuan yang tidak dapat dicapai dengan menggunakan prosedur prosedur statistik atau dengan cara kuantifikasi lainnya, karena data bukan berupa angka dan data berupa deskriptif.

Dalam penelitian ini yang menjadi instrumen penelitian adalah sebagai berikut, Public Relations and Quality Service, Manager Marketing, dan Customer. Pengumpulan data akan dilakukan dengan metode survei lapangan. Pencatatan data akan 
dilakukan paa waktu yang sudah ditentukan oleh Pihak RS. Husada Utama dan peneliti. Sebelum mengumpulkan data, peneliti wajib untuk mengikuti prosedur yang berlaku disana. Dalam penelitian ini, peneliti menggunakan teknik pengambilan data berupa wawancara. Wawancara adalah bentuk komunikasi antara dua orang, melibatkan seseorang yang ingin memperoleh informasi dari seorang lainnya dengan mengajukan pertanyaan - pertanyaan, berdasarkan tujuan tertentu.

\section{HASIL DAN PEMBAHASAN}

Menurut Keller terdapat 4 indikator untuk melihat brand awareness. Peneliti akan menganalisis strategi brand awareness RS Husada Utama dari sajian data yang sudah dipaparkan sebelumnya.

A. Recall

Recall adalah dimana strategi RS Husada Utama Surabaya untuk dapat membuat konsumen mengingat RS Husada Utama Surabaya. RS HU memanfaatkan bentuk gedung yang dimilikinya. Gedung yang tinggi dan megah adalah salah satu cara mudah untuk dapat membuat ingat tentang RS HU. Lokasi RS HU yang berada di Jl. Dr. Moestopo no 31 - 35 Surabaya juga adalah salah satu keuntungan.

RS HU berdiri megah diantara pemberhentian traffic light dari 4 arah. Yaitu dari Jalan Dharmahusada, Jalan Dharmawangsa, Jalan Dr.Moestopo, dan Jalan Tambang Boyo. Masyarakat yang sedang berhenti ketika lampu rambu lalu lintas berwarna merah, mereka dapat melihat gedung RS HU. Selanjutnya, strategi RS HU untuk membuat masyarakat ingat dengan RS HU adalah menjalin kerjasama dengan Department Store. Selanjutnya, juga ada bentuk kerjasama dimana anggota (member) pusat perbelanjaan tersebut juga menjadi member dari RS HU. Mereka mendapatkan broadcast messages tentang informasi promo atau kegiatan yang sedang berlangsung di RS HU.

B. Recognition

Recognition adalah dimana strategi untuk dapat mengenalkan Rumah Sakit Husada Utama Surabaya kepada masyarakat. RSHU memperkenalkan diri dengan menginformasikan tentang layanan unggulan kesehatan apa saja yang dimilikinya. RS Husada Utama memiliki 3 layanan unggulan kesehatan, yaitu program rehabilitas jantung, program waterbirth, dan program pencegahan osteoporosis. kode etik Rumah Sakit tertuliskan bahwa "Misi promosi dengan tidak hanya ditujukan untuk meningkatkan pengguna jasa (yang sekaligus akan meningkatkan pendapatan), akan tetapi juga harus sejalan dengan manfaat sosialnya. Selanjutnya, sistem promosi dengan bukan hanya menjual, tetapi sekaligus akan meningkatkan pengetahuan anggota masyarakat untuk memilih bentuk layanan kesehatan yang paling tepat bagi dirinya."

Berdasarkan kode etik tersebut, 80\% dari cara pengenalan pada masyarakat yang dilakukan oleh RS $\mathrm{HU}$, menggunakan edukasi. Edukasi ini dilakukan dengan banyak cara. Edukasi berupa seminar, program talkshow pada media massa, informasi sebuah penyakit melalui brosur, dan juga artikel di website.

Tidak hanya edukasi berupa seminar untuk dokter saja, RSHU juga membuat seminar ilmiah untuk para dokter. Contohnya, RS HU mengadakan seminar yang menginformasikan bahwa RS HU memiliki klinik bedah syaraf anak satu - satu nya di Indonesia. Seminar

ISSN 2338 - 0861 (cetak); e-ISSN 2621 - 8712 (online)

website : http://spektrum.stikosa-aws.ac.id 
tersebut bertujuan untuk mengenalkan dan memberi informasi kepada para dokter bahwa RS HU memiliki klink bedah syaraf anak, sehingga para dokter dapat merekomendasikan RS HU pada pasiennya yang membutuhkan. Selain seminar, edukasi yang dilakukan RS HU juga berupa penyampaian informasi kesehatan melalui media massa. Dalam pengenalan melalui media massa, RS HU bekerjasama dengan 3 media massa yaitu BBS TV, Radio Sas Fm, dan Radio Global Female.

Selanjutnya, RS Husada Utama mengenalkan motto "Setia melayani dengan kasih sayang" kepada masyarakat. Motto tersebut menjelaskan bahwa RS Husada Utama mengutamakan pelayanan agar dapat membuat pasien merasa nyaman. Motto ini tercerminkan oleh seluruh karyawan RS HU yang harus bersikap ramah kepada pengunjung RS Husada Utama. Sikap ramah ini ditunjukkan mulai dari front office, satpam, perawat, dokter, dan semua karyawan RS HU.

\section{Purchase}

Pada indikator purchase melihat strategi RS Husada Utama agar dapat menjadi pilihan alternatif ketika masyarakat membutuhkan tindakan medis. Strategi RS Husada Utama diantara lainnya adalah mengunggulkan kenyamanan. RS HU sangat mengutamakan kenyamanan, mulai dari kenyamanan dokter, obat, dan perawat. RS HU menyediakan fasilitas yang nyaman untuk pasien dan penunggu seperti, memberikan membedakan tiap lantai tempat praktik dokter. Dokter umum sampai dokter bedah plastik terdapat pada lantai 2, dokter ibu dan anak ada di lantai 4, dan untuk pasien kanker, onkologi, dan sejenisnya, gedung dipisah dari gedung utama RS HU.
Gedung tersebut ada di belakang, dekat tempat parkir RS HU.

Kenyamanan yang difasilitasi oleh RS HU tidak hanya kenyamanan untuk pasien, melainkan juga kenyamanan untuk penunggu. RS HU menyadarkan pada customer bahwa RS HU memiliki kualitas yang terjamin, dan harga yang sudah ditetapkan disini sesuai dengan fasilitas apa yang didapatkan.

Strategi lain, RS HU juga memiliki keunggulan fasilitas yang jarang bahkan tidak dimiliki oleh Rumah Sakit lain. Seperti fasilitas rehabilitasi jantung, program waterbirth, dan pencegahan osteoporosis.

D. Consumption

Consumption adalah strategi RS Husada Utama untuk membuat customer tetap mengingat RS Husada Utama meskipun sedang menggunakan Rumah Sakit lain. Kenyamanan adalah satu kunci dimana membuat pasien akan merasa puas ketika berobat di RS Husada Utama Surabaya. Dengan sesama rumah sakit tipe $b$ yang lain harga yang diberikan oleh RS HU dikatakan sama. Namun RS HU memiliki strategi dengan meberikan kenyamanan fasilitas hingga pasien merasa bahwa kualitas RS HU sesuai dengan harga.

RS HU percaya bahwa ketika pasien merasa puas ia akan mengingat kualitas RS HU meskipun sedang menggunakan RS lain. Dengan kenyamanan tersebut, juga dapat membuat pasien kembali ke RSHU jika membutuhkan tindakan medis. Bagi RS HU.

Bekerjasama dengan BPJS juga merupakan salah satu strategi agar RS HU dapat diingat meskipun pasien menggunakan Rumah Sakit lain. Pasien BPJS yang berasal dari semua kalangan, sehingga RS HU berpeluang besar untuk melayani semua kalangan.

ISSN 2338 - 0861 (cetak); e-ISSN 2621 - 8712 (online)

website : http://spektrum.stikosa-aws.ac.id 


\section{Strategi Publisitas Dalam Meningkatkan Brand Awareness \\ Publisitas adalah} penyebarluasan informasi berbasis aksi kehumasan dalam pemberitaan. Pemberitaan tentunya berkaitan dengan media. Humas RS Husada Utama menjalin kerjasama dengan media massa untuk dapat membantu menyebarluaskan informasi tentang RS Husada Utama. Strategi brand awareness yang sudah dipersiapkan tidak akan banyak sampai ke masyarakat tanpa bantuan media.

Humas RS Husada Utama menjaga hubungan personalitas dengan para awak media, ia merangkul dan menjadikan awak media sahabat. Humas RS Husada Utama tidak segan untuk saling membantu dengan media. Kedekatan yang terjalin antara humas RS Husada Utama dengan media membuat pemberitaan oleh media dapat diarahkan oleh humas RS HU. Hal tersebut sesuai dengan pernyataan Frank Jefkins yaitu "suatu kegiatan untuk mencapai publikasi atau penyiaran berita semaksimal mungkin, sedangkan informasi yang disebarkan melalui hubungan masyarakat adalah untuk menciptakan pengenalan dan pengertian."

Seitel mendefinisikan praktisi kehumasan sebagai a professional communicator. Hal ini mendefinisikan bahwa seorang komunikator harus bisa profesional dengan mengindahkan manajemen komunikasi sehingga dapat menghindari efek negatif dari komunikasi yang timbul. Dengan ini humas RS HU dituntut untuk benar benar mengerti pesan seperti apa yang relevan untuk publik $A, B$, dan $C$. Media apa pula yang paling efektif menjangkau target, serta teknik komunikasi seperti apa yang paling baik.
RS Husada Utama telah menjalin kerjasama yang cukup lama dengan 3 media, yaitu BBS TV, Radio SAS Fm dan Radio Global Female. RS HU bekerjasama dengan 3 media tersebut karena adanya persetujuan dengan sistem barter. RSHU tidak bekerjasama dengan media yang memasukkan RS HU dalam kategori iklan, hal tersebut karena keterbatasan anggaran. Namun, RS HU mengaku tidak masalah dengan 3 media tersebut karena target usia dari segmentasi RS HU adalah usia produktif, dan hal tersebut sesuai dengan segmentasi pendengar 3 media.

Sesuai dengan rencana program PRO/Konsultan PR menurut Cutlip, Center \& Brooom dimana terdapat pola definition of publics yang berarti menentukan publik yang akan dituju, lalu selection of media and techinques, memilih media dan teknisnya. Pemilihan media massa seharusnya sesuai dengan visi, misi, dan khayalak sasaran (public audience) dari RS Husada Utama. Tidak hanya karena keterbatasan anggaran, lalu RS Husada Utama mengandalkan pada media yang dapat menggunakan sistem barter.

Kerjasama dengan pers akan menghasilkan frekuensi publisitas yang cukup tinggi. Dampak pemberitaan tersbut baik yang bersifat efek keserampakan, efek dramatisir, atau efek publisitas tinggi dan memiliki pengaruh yang luar biasa terhadap pembentukan opini publik dalam waktu yang relatif singkat, yang tersebar di berbagai itempat dalam waktu bersamaan. Dengan adanya publisitas oleh media massa, berdampak pada banyak pasien yang mengenal dokter dan RS Husada Utama. Mereka mengenal dokter RS HU melalui program talkshow yang ditayangkan pada

ISSN 2338 - 0861 (cetak); e-ISSN 2621 - 8712 (online)

website : http://spektrum.stikosa-aws.ac.id 
media, bahkan salah satu dokter RS HU memiliki fans, yaitu dr. Heru Wijono, SpPD.

Tidak hanya pada media massa, RS HU juga memiliki media sosial untuk menunjang publisitas yaitu facebook, twitter, dan instagram. Media sosial tersebut dibuat oleh marketing lalu dikelola oleh humas RS HU. Marketing RS HU memiliki terobosan baru dalam media publikasi kegiatan,yaitu dengan membuat e-flyer/imooji untuk tiap kegiatan atau promo yang sedang berlangsung di RS HU. Bagi RS HU, eflyer/imooji mendapatkan antusias lebih banyak. E-flyer tersebut juga mudah tersebar, bahkan ke daerah yang jauh. Cara menyebarkannya bisa menggunakan broadcast messages via whatsapp.

Peranan hubungan media dan pers dalam kehumasan tersebut dapat sebagai saluran (channel) dalam penyampaian pesan maka upaya peningkatan pengenalan (awareness) dan informasi atau pemberitaan dari pihak publikasi humas merupakan prioritas utama. RS Husada Utama menggunakan media massa dan media sosial untuk memberikan informasi tentang edukasi kesehatan, layanan unggulan kesehatan, dan kegiatan RS Husada Utama sehingga masyarakat dapat mengenal dan mengingat RS HU.

\begin{tabular}{llr}
\multicolumn{2}{c}{ Berdasarkan data } & yang \\
diperoleh & peneliti & melalui \\
perbincangan & dengan & beberapa
\end{tabular} konsumen (pasien dan keluarga pasien) RS Husada Utama, peneliti mendapatkan gambaran bahwa pasien dan keluarga pasien yang mengetahui dan mengenal RS Husada Utama dikarenakan sering melintasi lokasi Jl. Dr. Moestopo, dan melihat gedung RSHU. Tidak hanya melintasi lokasi, namun ada yang mengetahui karena membaca website RS Husada
Utama, mendapatkan rekomendasi dari keluarga, dan mendapat rujukan dari dokter atau BPJS. Bentuk gedung yang megah dan menjulang tinggi, juga menjadi salah satu strategi jitu dimana dapat menjadi eye catching terhadap setiap masyarakat yang melintasi lokasi daerah sekitar RS Husada Utama.

Pengunjung RS Husada Utama mayoritas berasal dari Surabaya. Peneliti juga menemukan 2 konsumen berasal dari Tuban dan Bangkalan, mereka datang ke RS Husada Utama dikarenakan memang sudah cocok dengan dokter spesialis anak di RS HU. Ketika konsumen disinggung tentang apa yang mereka ingat dari RS Husada Utama, mayoritas mereka menggambarkan fasilitas RSHU yang lengkap, dokter berkualitas, serta perawat dan staff yang ramah.

\section{KESIMPULAN}

Simpulan yang dapat dipaparkan dari hasil penelitian mengenai "Strategi Publisitas Dalam Meningkatkan Brand Awareness RS Husada Utama Surabaya" adalah sebagai berikut :

1. Strategi Brand Awareness RS HU meliputi 4 indikator yaitu yang pertama yaitu recall, RS Husada Utama berlokasi di Jl. Prof. Dr. Mustopo no $31 \quad-35$ Surabaya, memiliki bentuk gedung yang megah dan tinggi untuk menarik masyarakat yang melintas disekitar lokasi tersebut. Dimana ini berkaitan dengan konsep marketing place. Tidak hanya dengan lokasinya, RS HU juga menjalin kerjasama dengan department store untuk membuat pasien atau calon pasien ingat tentang RS $\mathrm{H}$, dan hal ini berkaitan dengan konspe marketing promotion. Selanjutnya yaitu indikator recognition, RS HU mengenalkan 
kepada masyarakat tentang layanan kesehatan yang ditawarkan oleh RS HU. Hal tersebut berkaitan dengan konsep marketing product. Kemudian indikator purchase, RS HU menyuguhkan harga yang sebanding dengan fasilitas yang tersedia di RS HU. Kenyamanan dan keramahan merupakan prioritas utama, sehingga akan membuat pasien tidak merasa berat untuk harga yang ada di RS HU. Dalam indikator ini, berkaitan dengan konsep marketing price. Dan yang terakhir indikator consumption, RS HU menjalin kerjasama dengan BPJS. Hal tersebut berkaitan dengan konsep marketing promotion.

2. RS Husada Utama memiliki khalayak sasaran yaitu menengah ke atas. Hal itu terbukti karena RSHU menjalin kerjasama dengan Department Store yang memiliki segmentasi menengah ke atas. Pusat perbelanjaan tersebut yaitu (Grand City, Galaxy Mall, dan Pasar Atum). Namun sebagai pelayanan kesehatan, RSHU juga mencoba untuk merangkul semua kalangan, RS HU bekerjasama dengan BPJS (Badan Penyelenggara Jaminan Sosial) per tanggal 1 September 2016. RS HU juga membuat berbagai promo potongan harga beberapa layanan kesehatan yang ditawarkan RS Husada Utama. RS HU menginformasikan pada masyarakat bahwa mereka tidak mahal dan harga yang ditawarkan sesuai dengan fasilitas yang didapatkan.

3.Strategi publisitas dalam meningkatkan brand awareness RS Husada Utama adalah dengan memberikan informasi kepada masyarakat tentang layanan unggulan kesehatan RS Husada Utama. Lalu mengenalkan kepada masyarakat menggunakan metode soft selling, dimana kebijakan RS HU adalah memberikan edukasi kesehatan kepada masyarakat. Hal tersebut sesuai dengan kode etik promosi Rumah Sakit yang berlaku.

Edukasi dapat berupa seminar, program talkshow kesehatan, dan kegiatan lainnya. Kegiatan edukasi bekerjasama dengan media massa untuk dapat menunjang publisitas RS Husada Utama. Media massa merupakan salah satu cara yang efektif untuk pengenalan (awareness) masyarakat terhadap RS Husada Utama. Namun di RS HU, tidak ada proses pemilihan media yang cocok dengan target audience yang ingin dituju. Humas RS Husada memilih berdasarkan hal teknis berkaitan dengan sistem barter agar dapat menekan anggaran biaya.

4.Dari hasil wawancara peneliti dengan beberapa konsumen dapat digambarkan bahwa mayoritas konsumen mengenal RS HU karena sering melintas di daerah RS Husada Utama. RS Husada Utama belum memaksimalkan penggunaan media relations dalam meningkatkan publisitas. Namun, RS Husada Utama sudah benar - benar mengutamakan kenyamanan fasilitas bagi pasien dan penunggu pasien, dimana seluruh konsumen yang berbincang dengan peneliti mengakui bahwa merasa nyaman ketika berobat di RS Husada Utama. Namun ada satu hal yang diungungkapkan sedikit kritik tentang toilet umum yang hanya dapat digunakan 1 saja. Hal tersebut membuat konsumen sedikit tidak nyaman, tetapi ia dan seluuh konsumen lain yang berbicara dengan peneliti, tetap,

selalu datang ke RS HU jika membutuhkan tindakan pelayanan medis.

\section{DAFTAR PUSTAKA}

ISSN 2338 - 0861 (cetak); e-ISSN 2621 - 8712 (online)

website : http://spektrum.stikosa-aws.ac.id 
Hermawan, Agus. 2012. Komunikasi Pemasaran. Jakarta: Erlangga

J. Moleong, Lexy. 2007. Metodologi Penelitian Kualititatif. Bandung: Remaja Rosdakarya

Nasrullah, Rulli dan Emeraldy Chatra. 2008.Public Relations. Bandung: PT Salamadani Pustaka Semesta

Ruslan, Rosady. 2003. Metode Penelitian Public Relation dan Komunikasi. Jakarta: PT Raja Grafindo

Ruslan, Rosady. 2016. Manajaemen PR dan Media Komunikasi. Jakarta: Rajawali Pers

Shimp, Terence.2014. Komunikasi Pemasaran dalam Periklanan dan Promosi. Jakarta: Salemba Empat

Soehadi, Agus W. 2005.Effective Branding. Bandung: Quantum BisnisManajemen

Sugiyono. Metode Penelitian Kuantitatif Kualititatif dan R\&D. Bandung: Alfabeta

Suryanto dan Syariffudin. 2016. Public Relations.Yogyakarta: Andi Offset

Untoro. 2011. Pengembangan Strategi Pemasaran Rumah Sakit Ketergantungan Obat Jakarta. Jakarta: Universitas Indonesia

Yuliana, Nina. 2014. Media Relations. Yogyakarta: Untirta.

Karya Ilmiah :

Alvionita, Bella. 2015. Skripsi. Strategi Brand Image Hotel Oval Surabaya dalam Meningkatkan Loyalitas Konsumen. Surabaya: Stikosa AWS

Hermawanti, Tanti.et al. "Strategi Komunikasi Pemasaran Sebagai Peningkatan UpayaPublisitas". www.jurnalkommas.com/docs/j urnal\%20tanti\%20_fix_.pdf. (Diakses pada 13 Maret 2017)

Kurniadi, Fredy dan Didik Hariyanto. 2013. "Strategi Komunikasi Pemasaran Medical Representative". KANAL.Vol.1 No

ISSN 2338 - 0861 (cetak); e-ISSN 2621 - 8712 (online) website : http://spektrum.stikosa-aws.ac.id 